\title{
EXPERIMENTAL STUDIES ON PLANTS OF LOTUS CORNICULATIS L. FROM ANGLESEY POLY- MORPHIC FOR CYANOGENESIS
}

\author{
RICHARD KEYMER and W. M. ELLIS \\ Unit of Genetics, The University, Hull HU6 7RX
}

Received 2.vi.77

\begin{abstract}
SUMMARY
Experiments on plants and animals from Porthdafarch, Anglesey, were designed to determine the effects of salt (both as salt spray and saline soil water), of grazing, and of trampling on cyanogenic and acyanogenic plants of Lotus corniculatus L. Two species of snails, Helicella itala (L.) and Cochlicella acuta (Müller), were found to be differential and selective herbivores of acyanogenic plants of $L$. corniculatus. The extrapolation of the experimental results to the field situation, previously reported, is discussed.
\end{abstract}

\section{Introduction}

IN the previous paper in this series (Ellis, Keymer and Jones, 1977c) we reported ecological studies on natural populations of Lotus corniculatus L. on Holy Island, Anglesey. These field studies detected several possible selective agents affecting the polymorphism of cyanogenesis in those populations, but did not answer the questions:

(i) Is salt tolerance associated with cyanogenesis in L. corniculatus?

(ii) Are the molluscs, Helicella itala (L.) and Cochlicella acuta (Müller) differential or selective herbivores of acyanogenic plants of $L$. corniculatus?

(iii) Does uniform grazing have a differential effect on cyanogenic and acyanogenic plants of $L$. corniculatus?

(iv) Does trampling have a differential effect on cyanogenic and acyanogenic plants of $L$. corniculatus?

This report presents the results of experimental work designed to answer these questions, using plants and animals collected from the Holy Island populations.

\section{Materials And methods}

Stock plants for use in the experiments were taken as cuttings from 70 plants growing on the cliff and 70 growing inland at Porthdafarch, Anglesey. The detailed description of the habitat will be found in Ellis, Keymer and Jones (1977c) and in Keymer (1978). The cuttings were grown in a mist unit in a peat and grit rooting mixture and were potted-on in John Innes No. 2 Compost when they were 6 weeks old. They were tested for cyanogenesis at regular intervals and plants with stable and unstable phenotypic expression were isolated (Ellis, Keymer and Jones, 1977b). In the experiments described in this paper only the stable stock plants were used as the source of the clonal material, and all the propagules were tested for cyano- 
genesis during the course of every experiment to ensure that the phenotypes were being expressed under the experimental conditions. The methods of testing leaves for cyanogenesis have been given in detail elsewhere (Jones, $1966,1977)$.

The experiments were designed to account for variation between treatments $(\mathrm{T})$, areas $(\mathrm{A})$, phenotypes $(\mathrm{Ph})$, plants $(\mathrm{Pl})$ and ramets $(\mathrm{Ra})$ and the numbers of each of these are shown in the tables of results as a total $\mathrm{N}=\mathrm{a}: b \mathrm{~T} \times c \mathrm{~A} \times d \mathrm{Ph} \times f \mathrm{Pl} \times g \mathrm{Ra}(e . g$. table 2). Because of the limits of space on the experimental design and the limits of time on the numbers that could be accurately scored, the area or the ramet components were omitted from some experiments. In order to economise, most of the experiments considered only two phenotypes, cyanogenic $(+)$ and acyanogenic, the latter actually including the three acyanogenic phenotypes (+-, - + and - -). Where the four phenotypes were distinguished the value of $f$ was limited to 3 because only three stable -+ stock plants were available.

\section{(i) Salt tolerance}

In a maritime habitat salinity in the environment may affect plants both as salt spray on the foliage and by the high osmotic potential of saline soil water.

\section{(a) Salt spray}

The effect of salt spray on cyanogenic and acyanogenic plants of $L$. corniculatus was estimated by exposing them twice daily to the salt spray of a mist unit connected to a sea-water reservoir. Spraying was regulated by a time-clock controlling an electronic valve situated at the outlet of the reservoir, so that sea water was sprayed over the plants in bursts of 14 seconds every 10 minutes for 1.5 hours at 12 hourly intervals. This timing was chosen to correspond with the periods on either side of the two high tides experienced daily when the cliff top vegetation would be most likely to be subjected to salt spray.

The experimental plants were propagated in a mist unit for 4 weeks, then potted and grown for a further 13 weeks in a glasshouse before being exposed to salt spray. At the end of each experiment the plants were moved to an adjacent bench in the glasshouse and 4 weeks later they were scored as dead (when no green foliage was present) or alive.

Two series of experiments were completed on plants which were arranged in randomised blocks during the experiments. The first series was designed to assess the variation in salt tolerance within clones between the two phenotypes using five plants per phenotype and eight ramets per plant. Five experiments were carried out, each on new propagules, with treatments of salt spray for 2, 3, 4 and 6 days.

In the second series, the variation in salt tolerance between the two phenotypes and between plants from the cliff and the mound (see Ellis, Keymer and Jones, $1977 c$ for a description of these localities) was assessed using 10 plants per phenotype and two ramets per plant from the two areas. Four experiments were carried out, each on new propagules, with treatments for salt spray for $3,4,4.5$ and 5 days.

The analysis of the results was by $\chi^{2}$ tests using Yates correction. Where zeros were scored exact probabilities were calculated. 


\section{(b) Saline soil water}

The effect of saline soil water was estimated by the measurement of root elongation in culture and treatment solutions, a method first described by Wilkins $(1957,1960)$ in work on heavy metal tolerance in the grass, Festuca ovina $\mathrm{L}$. Since then it has been used to measure salt tolerance in other grasses (e.g. Hannon and Bradshaw, 1968; Tiku and Snaydon, 1971). An index of tolerance is constructed from the measurement of two growth increments on the same root, one after 3 days in the culture solution and the second after 3 days in the treatment solution, that is, the culture solution to which sodium chloride has been added. Similar work on grasses (Venables, pers. comm.) had indicated that the culture solution described by Arnon and Hoagland (1940), without the addition of micronutrients, would be suitable for this work. Because it was possible that L corniculatus plants from Porthdafarch could have a salt requirement, a small amount of $\mathrm{NaCl}$ was added to the culture solution (table 1). It was hoped that this would also protect the plants from salt shock when they were transferred to the treatment solutions. The five treatment solutions used were $0,50,100$, 150 and $200 \mathrm{mg}$ equiv. $\mathrm{NaCl}$ per litre. The experiment was designed to assess the differences between cyanogenic and acyanogenic plants from the cliff and the mound and so we used 10 plants per phenotype from both areas for the five treatments. They were propagated in a mist unit for 3 weeks before being transferred to the culture solutions. These were contained in 10 aerated perspex tanks set up on a laboratory bench, illuminated by northern daylight. The plants were supported within perspex tubes on polystyrene rafts in the culture solutions. The tanks were covered in black plastic up to the level of the rafts so that the roots would not be exposed to light. The existing roots were cut off the plants when they were placed in the tanks. During the experiment the mean maximum temperature was $24 \cdot 9^{\circ} \mathrm{C}$ and the mean minimum temperature was $17 \cdot 4^{\circ} \mathrm{C}$.

\section{TABLE 1}

Composition of the nutrient solution used in the salt tolerance experiments

\begin{tabular}{|c|c|c|c|c|c|}
\hline Element & $\mathrm{mM}$ & mg equiv/l & p.p.m. & Salt used & $g / 1$ \\
\hline $\mathrm{Ca}$ & $3 \cdot 0$ & $6 \cdot 0$ & 120 & $\mathrm{Ca}\left(\mathrm{NO}_{3}\right)_{2} \cdot 4 \mathrm{H}_{2} \mathrm{O}$ & $0 \cdot 708$ \\
\hline $\mathrm{Mg}$ & $2 \cdot 0$ & $4 \cdot 0$ & 48 & $\mathrm{MgSO}_{4} \cdot 7 \mathrm{H}_{2} \mathrm{O}$ & 0.490 \\
\hline $\mathrm{K}$ & $10 \cdot 0$ & $10 \cdot 0$ & 390 & $\mathrm{KNO}_{3}$ & $1 \cdot 020$ \\
\hline $\mathrm{P}$ as $\mathrm{PO}_{4}$ & $2 \cdot 0$ & $6 \cdot 0$ & 62 & $\mathrm{NH}_{4} \mathrm{H}_{2} \mathrm{PO}_{4}$ & $0 \cdot 230$ \\
\hline $\mathrm{N}$ as $\mathrm{NH}_{4}$ & $2 \cdot 0$ & $2 \cdot 0$ & 28 & $\mathrm{NH}_{4} \mathrm{H}_{2} \mathrm{PO}_{4}$ & $0 \cdot 230$ \\
\hline $\mathrm{N}$ as $\mathrm{NO}_{3}$ & $16 \cdot 0$ & $16 \cdot 0$ & 224 & $\mathrm{CA}\left(\mathrm{NO}_{3}\right)_{2} \cdot 4 \mathrm{H}_{2} \mathrm{O} ; \mathrm{KNO}_{3}$ & - \\
\hline $\mathrm{S}$ & $2 \cdot 0$ & $4 \cdot 0$ & 64 & $\mathrm{MgSO}_{4} \cdot 7 \mathrm{H}_{2} \mathrm{O}$ & $0 \cdot 490$ \\
\hline $\mathrm{Na}$ & $1 \cdot 3$ & $1 \cdot 3$ & 30 & $\mathrm{NaCl}$ & 0.076 \\
\hline $\mathrm{Cl}$ & $1 \cdot 3$ & $1 \cdot 3$ & 46 & $\mathrm{NaCl}$ & 0.076 \\
\hline
\end{tabular}

The difference in the length of the longest new root measured on day 3 and again on day 6 was used as the growth increment in the culture solution. On day 6 the solutions were changed to fresh culture solutions to which the $\mathrm{NaCl}$ had been added. The second growth increment was measured as the growth over the 3 days, from day 9 to day 12, representing growth in the treatment solutions. Mean indices of tolerance were constructed from the measurements of these two increments as: 
Mean index of tolerance $=$

$$
=\frac{\text { mean increment of the longest root in treatment solution }}{\text { mean increment of the longest root in culture solution. }}
$$

Analyses of variance were carried out on the data for growth in the culture solutions and in the treatment solutions.

\section{(ii) Herbivore preference}

Differential and selective feeding experiments were completed on 35 H. itala and 20 C. acuta individuals, collected from the hollow and the mound at Porthdafarch, Anglesey. In these experiments each animal retained an individual identity. The animals in both species were divided into two groups. One group was fed plant material in the order cyanogenic, acyanogenic and then both phenotypes together and the other group was presented with the sequence acyanogenic, cyanogenic and both. This experimental design would detect whether differences in sequence would affect the feeding behaviour of the snails.

The feeding trials were carried out in a controlled environment cabinet with a day length of 8 hours, a day temperature of $20^{\circ} \mathrm{C}$ and a night temperature of $15^{\circ} \mathrm{C}$. Each trial took 3 days to complete. On day 1 each mollusc was placed in a petri dish with some damp sand and some bran. After it was found in preliminary experiments that these molluscs preferred eating filter paper to all other food, damp sand was used to maintain a high relative humidity in the petri dishes. On the 2nd day, the mollusc was transferred to a new petri dish with damp sand and no food and was starved for 24 hours. It was then transferred to a new petri dish to which a measured area of the appropriate leaves was added. After 24 hours the next trial began when the mollusc was placed in a new petri dish with damp sand and bran. The leaf area remaining uneaten was measured so that the actual area of leaf eaten in any trial could be calculated. Leaf areas were measured directly in $\mathrm{cm}^{2}$ using a portable area meter made by Lambda Instruments Corporation. Each of the leaf areas used in the analyses was the mean of three readings. Any leaves left were then tested for cyanogenesis to check that the phenotypes were being expressed under the conditions of the experiment. Differences in the area of leaf eaten between phenotypes and between experiments were assessed by analysis of variance.

\section{(iii) Grazing}

There is now considerable evidence that various animals selectively graze the acyanogenic phenotype of L. corniculatus (Jones, 1962; CrawfordSidebotham, 1972) and we have demonstrated the defensive function of cyanogenesis in the Anglesey populations (Ellis, Keymer and Jones, 1977a). The basic assumption, however, that grazing is deleterious to the plants has not been tested. Clearly grazing may affect both vegetative and sexual reproduction and we have no evidence as to the relative importance of clonal and seed contributions to successive generations in any population. There are two major difficulties in designing a grazing experiment: choosing a method of artificial grazing which is similar to the effect of herbivores, and choosing a growth parameter to measure that will give an accurate estimate of the effect both on vegetative and on sexual reproduction. 
The limitations of clipping the plant to simulate grazing have been discussed by Jameson (1963). Of particular importance with respect to mollusc grazing of $L$. corniculatus is the non-uniformity of grazing height and possible selective preference for a particular part of the plant; for example it has been observed in the laboratory that $H$. itala selects flowers in preference to leaves (Malan, 1973). Thus uniform clipping may be more severe on the plant than casual grazing by herbivores, especially if the simulated grazing removes meristems, for example, the axillary buds, from which regrowth occurs (Greub and Wedin, 1971).

Accurate measurements of vegetative and sexual reproduction are difficult for any species and in L. corniculatus are further complicated by the wide range of variation in growth habit (Seaney and Henson, 1970) and seed production (Jones, 1966). Unfortunately, yield measured as dry matter production, leaf area or crop growth rate does not necessarily equate with the number of new individuals produced by cloning and there is no convenient measure, as, for example, the number of tillers in grasses, which can be satisfactorily used to assess cloning ability. Moderate grazing is known to increase vegetative growth in L. corniculatus (Jameson, 1963; Greub and Wedin, 1971) and may, therefore, actually be advantageous to the selectively grazed phenotype. Furthermore, it has been shown that spring clipping of $L$. corniculatus may prolong the duration of flowering without reducing seed set, although clipping in June or during flowering does reduce it (Seaney and Henson, 1970).

Taking all these limitations into consideration, as well as the results of preliminary trials, we designed an experiment to assess the effect of clipping on the four phenotypes of $L$. corniculatus, using pod production as the growth parameter. Pod production is directly related to seed production and may also be related to the number of axillary buds, so that we hoped by this means to assess the effect of grazing on both sexual and vegetative reproduction. The plants were propagated in a mist unit, three plants per phenotype and three ramets per plant for each of the three treatments. When they were 5 weeks old, they were planted $15 \mathrm{~cm}$ apart in three randomised blocks in a cold frame, so that frost and herbivore stresses could be eliminated. Treatment commenced in late spring, after the plants had been allowed to grow over winter. In the preliminary experiment we found that the primary effect of vertical clipping (that is clipping to a particular height) was to remove upright flowers while having little effect on the prostrate foliage. We chose, therefore, to cut the plants back to a predetermined diameter. The three treatments consisted of a control block which was not clipped, and two experimental blocks in which individual plants were clipped to $12.5 \mathrm{~cm}$ and $7.5 \mathrm{~cm}$ diameters respectively. Clipping was carried out, at 4-weekly intervals, on 4th May and lst and 28th June and the numbers of pods per plant were scored on 30th July 1976. An analysis of variance was carried out to determine whether the differences in pod production between the phenotypes and between the treatments were significant.

\section{(iv) Trampling}

Trampling can act directly on the vegetation by bruising and crushing, and indirectly by changing such soil characteristics as bulk density and water content and so the effect of trampling may vary according to the type of

$40 / 2-B$ 
soil (Burden and Randerson, 1972; Liddle and Greig-Smith, 1975a, b). Our trampling experiment was carried out in the research garden of the University Botanic Gardens where the soil is a clay loam over a sandy clay loam with good drainage of water. Three treatments were used: no trampling, light trampling effected by walking over the plants once a day and heavy trampling by walking over the plants twice, sequentially, every day. Two phenotypes, cyanogenic and acyanogenic, were used in the experiment, two plants per phenotype and eight ramets per plant in each treatment. The plants were propagated in a mist unit in a warm glasshouse for 4 weeks and hardened off in a cool greenhouse for 2 weeks before being planted on 23rd April, $12.5 \mathrm{~cm}$ apart in the soil in three randomised blocks. Treatment commenced on 17 th June and continued on Mondays to Fridays inclusive until the results were scored on 20th September 1975 as the total number of pods per plant. Pod production was used as the growth parameter for the same reasons as in the uniform grazing experiment. The soil impaction for each treatment was measured by penetrometer readings and there were significant differences between the treatments $(P<0.001)$, the means of which are shown in table 12. The differences in pod production between the treatments and the phenotypes were assessed by analysis of variance.

\section{Results}

\section{(i) Salt tolerance}

From the results of both series of salt spray experiments it appears that a threshold in the application of salt spray is reached at approximately 4 days (or eight high tides) and that once this threshold is exceeded only a few plants are sufficiently salt tolerant to survive. There were no significant differences in survival either within clones or between phenotypes exposed to salt spray for any of the treatments in the first series of experiments (table 2). In the second series, there was one significant $\chi^{2}$ value (table 3 )

\section{TABLE 2}

Contingency $\chi^{2}$ values comparing survival within clones between phenotypes of plants from Porthdafarch in the first series of salt-spray experiments

$$
\mathrm{N}=400: 5 \mathrm{~T} \times 2 \mathrm{Ph} \times 5 \mathrm{Pl} \times 8 \mathrm{Ra}
$$

\begin{tabular}{|c|c|c|c|c|c|}
\hline \multirow{2}{*}{$\begin{array}{l}\text { Treatment } \\
\text { No. days spraying }\end{array}$} & \multicolumn{2}{|c|}{ Cyanogenic } & \multicolumn{2}{|c|}{ Acyanogenic } & \\
\hline & Alive & Dead & Alive & Dead & $\chi_{[1}^{2}$ \\
\hline 2 days & 33 & 7 & 31 & 9 & $0 \cdot 08$ \\
\hline 3 days & 35 & 5 & 29 & 11 & $\mathrm{I} \cdot \mathrm{S}$ \\
\hline 3 days & 32 & 8 & 28 & 12 & 0.6 \\
\hline 4 days & 12 & 28 & 6 & 24 & 1.7 \\
\hline 6 days & 3 & 37 & 3 & 37 & 0.0 \\
\hline
\end{tabular}

suggesting that acyanogenic plants from the mound were less tolerant of salt spray for 4 days. This difference would help to account for one of the significant values obtained from the comparisons of survival in plants from the two areas, irrespective of phenotype (table 4). None of the $\chi^{2}$ values for comparisons of survival in plants of the two phenotypes, irrespective of area 
TABLE 3

Contingency $\chi^{2}$ values comparing survival between plants of both phenotypes from the cliff and the mound at Porthdafarch in the second series of salt spray experiments

$$
\mathrm{N}=320: 4 \mathrm{~T} \times 2 \mathrm{~A} \times 2 \mathrm{Ph} \times 10 \mathrm{Pl} \times 2 \mathrm{Ra}
$$

$\begin{array}{lccccc}\text { Treatment } \\ \text { No. days spraying } & \overbrace{\text { Alive }}^{\text {Cyanogenic }} & \text { Dead } & \overbrace{\text { Alive }}^{\text {Acyanogenic }} & \\ \text { Dead } & \chi_{[1]}^{2} \\ 4 \text { days } & 18 & 2 & 20 & 0 & {[0 \cdot 24] \dagger} \\ 4.5 \text { days } & 18 & 2 & 19 & 1 & 0.00 \\ 5 \text { days } & 2 & 18 & 6 & 14 & 1.41 \\ & 3 & 17 & 5 & 15 & 0.16\end{array}$

\begin{tabular}{|c|c|c|c|c|c|}
\hline \multirow{3}{*}{$\begin{array}{l}\text { Treatment } \\
\text { No. days spraying }\end{array}$} & \multicolumn{4}{|c|}{ Mound } & \multirow[b]{3}{*}{$\chi_{[1]}^{2}$} \\
\hline & \multicolumn{2}{|c|}{ Cyanogenic } & \multicolumn{2}{|c|}{ Acyanogenic } & \\
\hline & Alive & Dead & Alive & Dead & \\
\hline 3 days & 18 & 2 & 13 & 7 & $2 \cdot 29$ \\
\hline 4 days & 17 & 3 & 9 & 11 & $5 \cdot 38 *$ \\
\hline 4.5 days & 3 & 17 & 6 & 14 & 0.57 \\
\hline 5 days & 0 & 20 & 1 & 19 & {$[0.50] \dagger$} \\
\hline
\end{tabular}

\section{TABLE 4}

Contingency $\chi^{2}$ values in the second series of salt spray experiments comparing the survival of plants (a) of the two phenotypes, irrespective of area, and (b) from the two areas, irrespective of phenotype

$$
\text { - } \mathrm{N}=320: 4 \mathrm{~T} \times 2 \mathrm{~A} \times 2 \mathrm{Ph} \times 10 \mathrm{Pl} \times 2 \mathrm{Ra}
$$

$\begin{array}{lcc}\text { Treatment } & \text { Phenotype } \times \text { Survival } & \text { Area } \times \text { Survival } \\ \text { No. days spraying } & \chi_{[1]}^{2} & \chi_{[1]}^{2} \\ 3 \text { days } & 0 \cdot 42 & 3 \cdot 79 \\ 4 \text { days } & 2 \cdot 69 & 7 \cdot 47^{*} \\ 4.5 \text { days } & 2 \cdot 69 & 0.00 \\ 5 \text { days } & 0.50 & 4.51^{*} \\ & * \mathrm{P}<0.05 . & \end{array}$

were significant. Possibly plants from the mound are less tolerant than plants from the cliff.

To confirm that the results of the second series of experiments had been correctly interpreted an analysis of variance was also completed on the data (table 5). The numbers 1 and 2 were used to convert the qualitative scores alive and dead respectively into a form that could be used in an analysis of variance. The results of the analysis do no more than confirm the conclusions already drawn, that is, that there were significant differences between the treatments and between the survival of coastal and inland plants. 
TABLE 5

Means and analysis of variance comparing the survival scores of cyanogenic and acyanogenic plants from the cliff and the mound in the second series of salt spray experiments

$$
\mathrm{N}=320: 4 \mathrm{~T} \times 2 \mathrm{~A} \times 2 \mathrm{Ph} \times 10 \mathrm{Pl} \times 2 \mathrm{Ra}
$$

\begin{tabular}{ccccc} 
Means & \multicolumn{3}{c}{ Mound } \\
No. days spraying & $\overbrace{\text { Cyanogenic }}^{\text {Cliff }}$ & $\overbrace{\text { Cyanogenic }}^{\text {Acyanogenic }}$ & Acyanogenic \\
3 days & 22 & 20 & 22 & 27 \\
4 days & 22 & 21 & 37 & 31 \\
4.5 days & 38 & 34 & 40 & 34 \\
5 days & 37 & 35 & & 39
\end{tabular}

Analysis of variance

\begin{tabular}{lcc}
\multicolumn{1}{c}{ Source } & d.f. & M.S. \\
Phenotypes & 1 & 0.00 \\
Treatments & 3 & $11 \cdot 91 * * *$ \\
Areas & 1 & $1 \cdot 80^{*}$ \\
Phenotype $\times$ Treatment & 3 & 0.48 \\
Phenotype $\times$ Area & 1 & $1 \cdot 01$ \\
Treatment $\times$ Area & 3 & $0 \cdot 32$ \\
Phenotype $\times$ Treatment $\times$ Area & 3 & $0 \cdot 21$ \\
Between plants within phenotypes & 144 & $0.33 * * *$ \\
Between ramets within plants & 160 & $0 \cdot 10$ \\
$\quad$ * P<0.05; & $* * * \mathrm{P}<0.001$.
\end{tabular}

More conclusive evidence of the differences in salt tolerance between phenotypes and areas came from the root growth experiments in the culture and the $\mathrm{NaCl}$ treatment solutions. The mean indices of tolerance of the cyanogenic phenotype from the cliff and both phenotypes from the mound were similar, falling from a mean of 0.51 to a mean of 0.10 (table 6). The acyanogenic plants from the cliff, however, grew similarly to all the other plants in the treatment solutions, but less than those in the culture solutions, so giving rise to higher indices of tolerance. The analysis of variance of growth in the culture solutions (table 7) shows that there was a significant difference between phenotypes and a significant phenotype $\times$ area interaction, the cyanogenic cliff plants growing the most and the acyanogenic cliff plants the least. On the other hand, in the treatment solutions (table 8), the only significant difference was between treatments, that is the growth of both phenotypes from both areas was suppressed to similar levels. Clearly, plants from the mound are less salt tolerant than acyanogenic plants from the cliff, a result which compares well with those from the salt spray experiments which showed that plants from the mound might be less tolerant than plants from the cliff. The most interesting result, however, is that cyanogenic plants from the cliff are less tolerant than the acyanogenic plants, implying that the latter may have some selective advantage in that habitat.

\section{(ii) Herbivore preferences}

The most important result of these experiments is that both $H$. itala and C. acuta are significantly differential and selective in their feeding on leaves 
TABLE 6

Mean indices of tolerance for the two phenotypes of $\mathrm{L}$. corniculatus plants from the cliff and the mound at Porthdafarch

$$
\mathrm{N}=200: 5 \mathrm{~T} \times 2 \mathrm{~A} \times 2 \mathrm{Ph} \times 10 \mathrm{Pl}
$$

Treatments mg equiv. $\mathrm{NaCl}$ per 1

\section{0}

100

150

200

\begin{tabular}{|c|c|}
\hline \multicolumn{2}{|c|}{ Cliff } \\
\hline Cyanogenic & Acyanogenic \\
\hline 0.51 & $1 \cdot 44$ \\
\hline 0.59 & 0.69 \\
\hline 0.40 & 0.68 \\
\hline $0 \cdot 13$ & 0.03 \\
\hline
\end{tabular}

TABLE 7

\begin{tabular}{|c|c|}
\hline Cyanogenic & Acyanogenic \\
\hline $0 \cdot 42$ & $0 \cdot 60$ \\
\hline 0.71 & 0.58 \\
\hline 0.44 & 0.40 \\
\hline $0 \cdot 10$ & 0.07 \\
\hline
\end{tabular}

Means and analysis of variance of root growth of plants of both phenotypes from the cliff and the mound at Porthdafarch grown in culture solution. The treatments were identical in this analysis all being the culture solution alone

$$
\mathrm{N}=200: 5 \mathrm{~T} \times 2 \mathrm{~A} \times 2 \mathrm{Ph} \times 10 \mathrm{Pl}
$$

Means (mm)

Treatments mg equiv. $\mathrm{NaCl}$ per 1

$$
\begin{aligned}
& 0 \\
& 0 \\
& 0
\end{aligned}
$$

\begin{tabular}{|c|c|}
\hline \multicolumn{2}{|c|}{ Mound } \\
\hline Cyanogenic & Acyanogenic \\
\hline $8 \cdot 025$ & $9 \cdot 775$ \\
\hline $10 \cdot 225$ & $9 \cdot 125$ \\
\hline $7 \cdot 375$ & $6 \cdot 825$ \\
\hline $8 \cdot 350$ & 8.975 \\
\hline $6 \cdot 500$ & $8 \cdot 125$ \\
\hline
\end{tabular}$$
0
$$$$
0
$$

$\begin{array}{cc}\overbrace{\text { Cyanogenic }} \text { Cliff } \\ 13.075 & \text { Acyanogenic } \\ 10 \cdot 825 & 4.300 \\ 10 \cdot 225 & 3 \cdot 750 \\ 13 \cdot 150 & 9.975 \\ 16.300 & 3.850 \\ & 5 \cdot 250\end{array}$

Analysis of variance

\begin{tabular}{lcc}
\multicolumn{1}{c}{ Source } & d.f. & M.S. \\
Phenotypes & 1 & $581 \cdot 40 * * *$ \\
Treatments & 4 & $1 \cdot 99$ \\
Areas & 1 & $27 \cdot 38$ \\
Phenotypes $\times$ Treatments & 4 & $30 \cdot 22$ \\
Phenotypes $\times$ Areas & 1 & $752 \cdot 72^{* * *}$ \\
Treatments $\times$ Areas & 4 & $60 \cdot 06$ \\
Phenotypes $\times$ Treatments $\times$ Areas & 4 & $65 \cdot 42$ \\
Between plants within phenotypes, & & \\
$\quad$ Treatments and Areas & 180 & $59 \cdot 94$ \\
& $* * *$ & $\mathrm{P}<0 \cdot 001$.
\end{tabular}

of $L$. corniculatus (tables 9, 10). They eat more acyanogenic than cyanogenic leaves when offered one or the other or a choice of both.

It is interesting that the sequence of the experiment did have a significant effect on the feeding behaviour of the snails and that the effect was the same for both species. The snails ate equal areas of acyanogenic leaves irrespective of sequence, but they ate almost twice as much of the cyanogenic leaves when they were offered them second, although still significantly less than they ate of the acyanogenic leaves. A possible explanation may be that the snails, having eaten acyanogenic leaves 3 days previously were prepared to sample more than one leaf before being discouraged by the cyanogenic leaves of the second trial. In the week immediately preceding the experiment they had been fed on bran only so that earlier experience is unlikely to 
TABLE 8

Means and analysis of variance of root growth of plants of both phenotypes from the cliff and the mound at Porthdafarch grown in $\mathrm{NaCl}$ treatment solutions

$$
\mathrm{N}=200 ; 5 \mathrm{~T} \times 2 \mathrm{~A} \times 2 \mathrm{Ph} \times 10 \mathrm{PI}
$$

Means (mm)

\begin{tabular}{|c|c|c|c|c|}
\hline \multirow{2}{*}{$\begin{array}{c}\text { Treatments } \\
\text { mg equiv. } \mathrm{NaCl} \text { per } 1\end{array}$} & \multicolumn{2}{|c|}{ Cliff } & \multicolumn{2}{|c|}{ Mound } \\
\hline & Cyanogenic & Acyanogenic & Cyanogenic & Acyanogenic \\
\hline 0 & $7 \cdot 875$ & $10 \cdot 425$ & $6 \cdot 325$ & $7 \cdot 050$ \\
\hline 50 & $5 \cdot 500$ & $5 \cdot 400$ & $4 \cdot 275$ & $5 \cdot 500$ \\
\hline 100 & $6 \cdot 075$ & $6 \cdot 900$ & $5 \cdot 250$ & 3.925 \\
\hline 150 & $5 \cdot 300$ & $2 \cdot 625$ & 3.675 & 3.575 \\
\hline 200 & $2 \cdot 150$ & $1 \cdot 500$ & $6 \cdot 500$ & $5 \cdot 750$ \\
\hline
\end{tabular}

Analysis of variance

\begin{tabular}{|c|c|c|}
\hline Source & d.f. & M.S. \\
\hline Phenotypes & I & 0.45 \\
\hline Treatments & 4 & $266 \cdot 78 * * *$ \\
\hline Areas & I & $67 \cdot 28$ \\
\hline Phenotypes $\times$ Treatments & 4 & $15 \cdot 04$ \\
\hline Phenotypes $\times$ Areas & I & 1.71 \\
\hline Treatments $\times$ Areas & 4 & $9 \cdot 16$ \\
\hline Phenotypes $\times$ Treatments $\times$ Areas & 4 & $12 \cdot 12$ \\
\hline Between plants within phenotypes, & & \\
\hline Treatments and Areas & 180 & $22 \cdot 64$ \\
\hline
\end{tabular}

have had any effect. In the field, of course, both kinds of leaf would be available at all times and it has been shown that $H$. itala foraging in the field has a high preference for $L$. corniculatus, which was identified in 62 per cent of the faeces examined (Malan, 1973). Although these results do not alter the conclusion that these species are differential and selective herbivores of acyanogenic L. corniculatus, it is apparent that care is necessary in the design of feeding experiments when feeding behaviour can be affected by sequence.

\section{(iii) Grazing}

It is clear from this experiment that grazing is deleterious (table 11) to all phenotypes of $L$. corniculatus, causing significant reductions in pod production. The most interesting result, however, is that non-selective grazing has differential effects on the four phenotypes, causing the least reduction on the -- plants and the most reduction on the +- and ++ plants. There were significant differences between phenotypes and between treatments, as well as a significant phenotype $\times$ treatment interaction. The differences between plants of the same phenotype were also significantly greater than between ramets of the same plant. It appears that under conditions of uniform grazing glucosidic plants $(++$ and +-$)$ produce only marginally more pods than aglucosidic plants $(-+$ and --$)$, whereas we can infer that under conditions of selective grazing of the acyanogenic phenotype $(+-,-+$ and --$)$, the cyanogenic phenotype would produce approximately three times as many pods. Because similar 


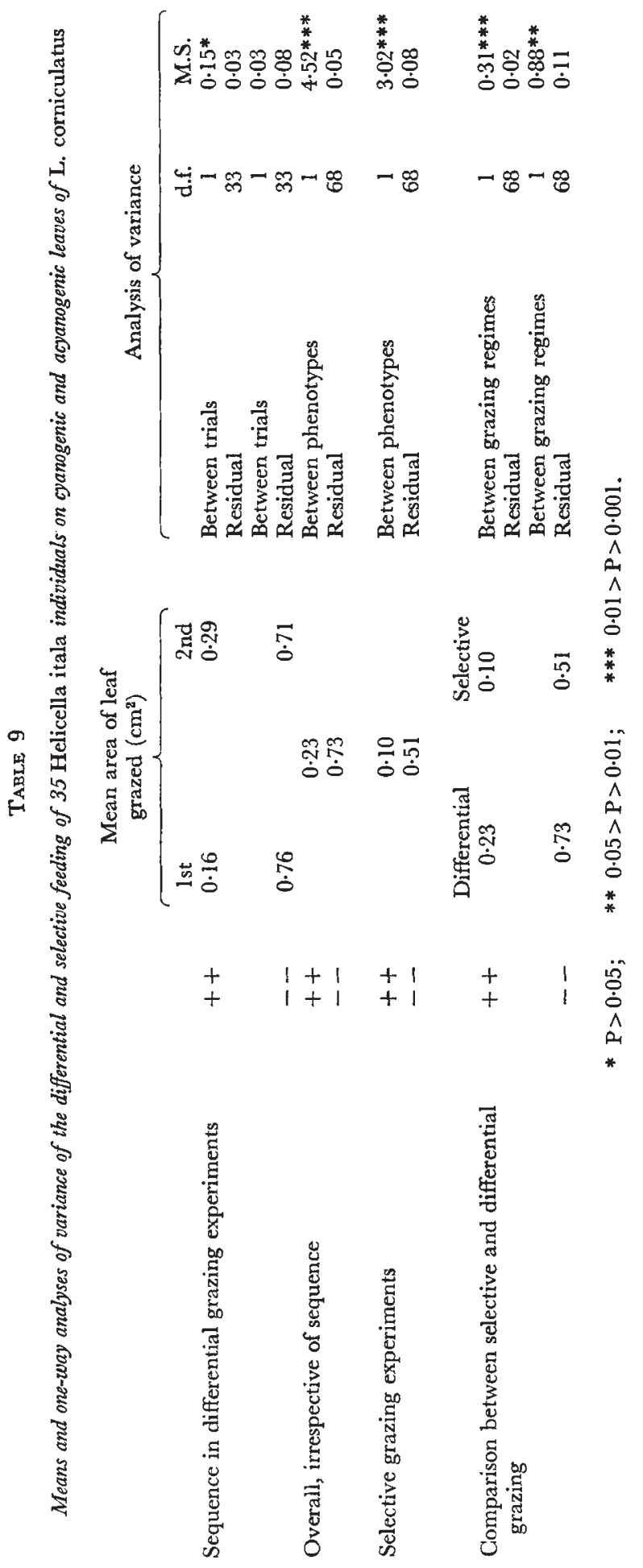




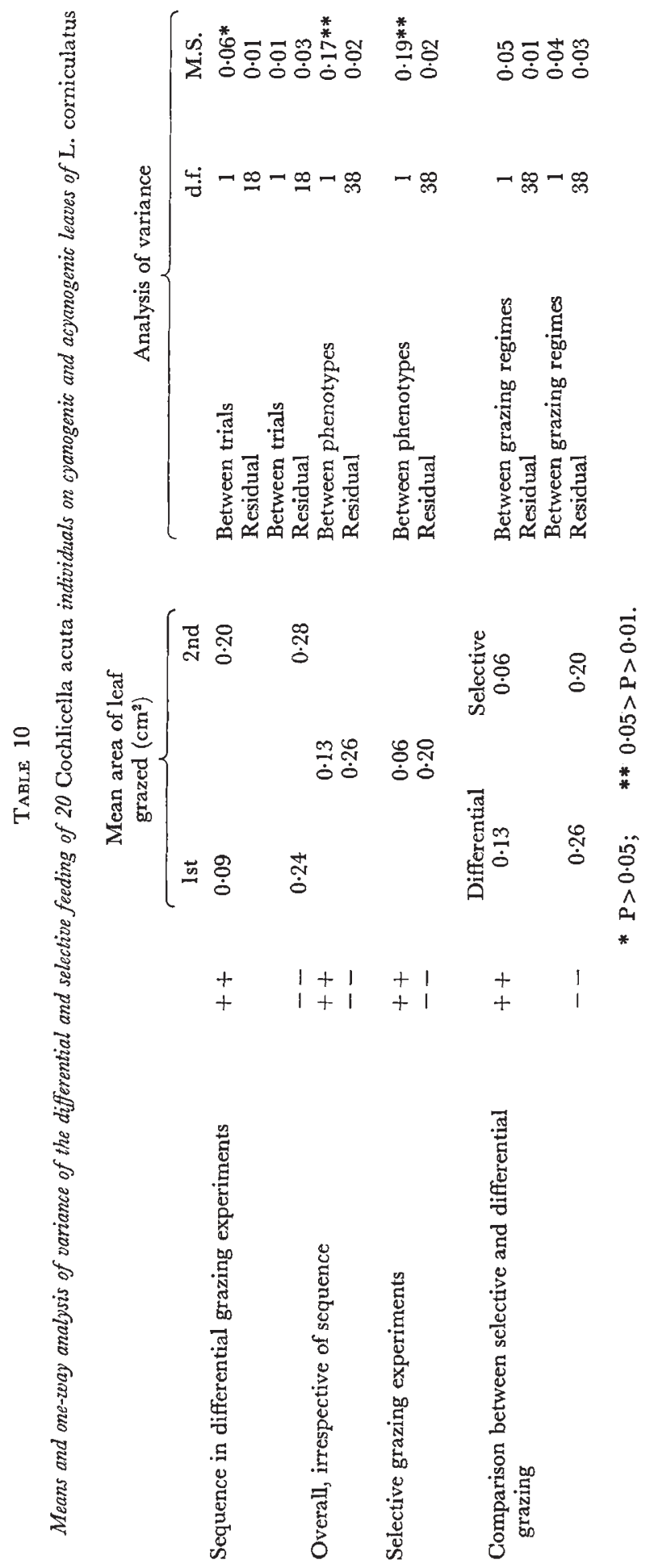


TABLE 11

Means and analysis of variance of pod number on plants of the four phenotypes subjected to three cycles of the three grazing treatments: no grazing; cutting to $12.5 \mathrm{~cm}$ diameter; cutting to $7.5 \mathrm{~cm}$ diameter

$$
\mathrm{N}=108: 3 \mathrm{~T} \times 4 \mathrm{Ph} \times 3 \mathrm{Pl} \times 3 \mathrm{Ra}
$$

Means of Pod Number

\begin{tabular}{lrrrr} 
Treatments & \multicolumn{1}{c}{+} & \multicolumn{1}{c}{+} & -+ & - \\
(no grazing) & 299.56 & 504.00 & 183.89 & 88.44 \\
$12.5 \mathrm{~cm}$ diam. & 81.67 & 90.33 & 62.67 & 65.89 \\
$7.5 \mathrm{~cm}$ diam. & 23.67 & 34.78 & 8.78 & 19.50
\end{tabular}

Analysis of variance

$\begin{array}{lrc} & \text { d.f. } & \text { M.S. } \\ \text { Phenotypt } & 3 & 116,896 \cdot 36 * * * \\ \text { Treatmen } & 2 & 604,201 \cdot 35 * * * \\ \text { Phenotypt } & 6 & 86,847 \cdot 27 * * * \\ \text { Between F.................notypes } & 24 & 19,439 \cdot 80 * * * \\ \text { Between ramets within plants } & 72 & 5,362 \cdot 36 \\ & * * * \quad P<0 \cdot 001 .\end{array}$

results were obtained from a grazing experiment on plants from Wharram Quarry, N. Yorkshire (Keymer, 1977), we can be confident that these effects were not due to a chance selection of unusual plants, even though the number of plants of each phenotype was small in our experiments.

\section{(iv) Trampling}

Trampling had a significant effect on pod production in both phenotypes of $L$. corniculatus, the differences between phenotypes and treatments both being significant. In addition the phenotype $\times$ treatment interaction mean square was significant (table 12). Plants of the cyanogenic phenotype produced more pods than those of the acyanogenic phenotype in all the treatments and are perhaps more tolerant of trampling. Because only a small number of plants were used in this experiment, we feel it would be unwise to draw any more general conclusion than that trampling reduces pod production in L. corniculatus and may therefore be a significant factor in the Porthdafarch environment.

\section{Discussion}

These experimental studies were designed to measure separately the effects on the polymorphism of cyanogenesis in L. corniculatus of environmental factors thought to be important at Porthdafarch and possibly along the whole south-west coast of Holy Island, Anglesey. We were able to show significant effects due to salt (both as salt spray and saline soil water) and grazing. We also showed that trampling has a significant effect on the plants, but its role as a selective agent acting on the polymorphism was undetermined.

Inter- and intra-specific variation in salt tolerance has been described in 


\section{TABLE 12}

Means and analysis of variance of pod number on plants of two phenotypes subjected to three trampling treatments: none, light, and heavy trampling

$$
\mathrm{N}=96: 3 \mathrm{~T} \times 2 \mathrm{Ph} \times 2 \mathrm{Pl} \times 8 \mathrm{Ra}
$$

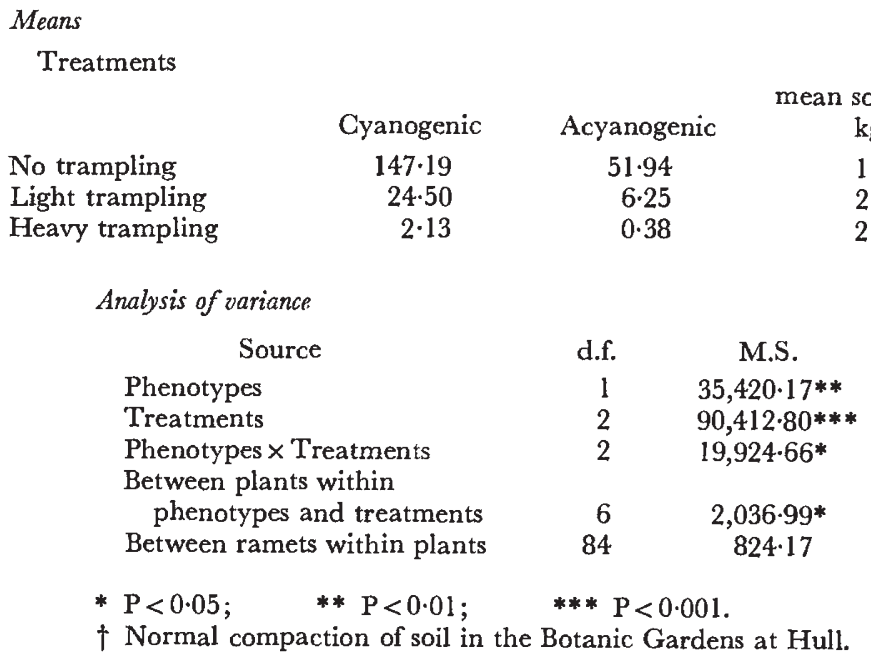

several species with coastal and inland ecotypes, such as $\mathcal{N i g e l l a}$ arvensis $\mathrm{L}$. (Waisel, 1959, 1972) and Agrostis stolonifera L. (Tiku and Snaydon, 1971), as well as species growing in saline and non-saline habitats, for example Typha spp. (McMillan, 1959) and Festuca rubra L. and A. stolonifera (Hannon and Bradshaw, 1968). In all these studies, attention has been focused on morphological and physiological adaptation to salt in the environment in the formation of salt tolerant ecotypes. Although we have noted comparable differences between coastal and inland plants of $L$. corniculatus (Ellis, Keymer and Jones, 1977c; Keymer, 1978; tables 3, 4, 5, 6, 7, 8), our main interest in this study has been the differences between the cyanogenic and the acyanogenic phenotypes with respect to salt tolerance.

Existing data on salt tolerance in L. corniculatus are scarce. Moreover, there is considerable confusion over nomenclature because $L$. tenuis W. et $\mathrm{K}$. has been called $L$. corniculatus $\mathrm{f}$. (or var.) tenuifolius in the past and there appear to be cultivars of $L$. corniculatus which are also called f. tenuifolius (de Nettancourt and Grant, 1963). Ayers (1948) states that in tests on forage crops at the U.S. Regional Salinity Laboratory, the plant he calls L. corniculatus var. tenuifolius had a high salt tolerance. Of the six species of legumes grown in the tests only $L$. corniculatus var. tenuifolius gave an appreciable yield in the high salt plot. Using the plasmolysis of cells after a period of submergence in $\mathrm{NaCl}$ solutions as an indication of protoplasmic tolerance, Repp et al. (1959), found that 50 per cent of the cells were killed in $0.5 \mathrm{~m}$ solutions, which was the same as for Trifolium repens L., but a higher concentration than for several other glycophytic species. Mudie (1974) describes L. corniculatus var. tenuifolius as a miohalophyte, 
one of several crops which are widely cultivated in non-saline soils, but which are noted for their relatively high salt tolerance in agricultural soils. This occurrence of salt tolerance among cultivars, which have gene pools restricted by controlled breeding and selection for characters other than salt tolerance, led Mudie to predict that wide variations in salt tolerance should occur among wild halophyte populations. There is also some evidence (Hannon and Bradshaw, 1968; Mudie, 1974) that certain ecotypes from non-saline soils may possess a potential salt tolerance unlike, for example, ecotypes of lead-intolerant species which show no special adaptation to tolerate toxic soils (Hannon and Bradshaw, 1968). If the potential salt tolerance of cyanogenic and acyanogenic phentoypes is similar, why do both phenotypes not occur with the same frequency on the cliff as inland at Porthdafarch? One possible explanation may be that the selective pressure giving cyanogenic plants an advantage inland is not operating on the cliff, for example selective herbivores may be absent. This we have shown to be true for the known selective herbivores of $L$. corniculatus present in the Porthdafarch environment, that is molluscs (Ellis et al., 1977a). However, other herbivores such as insects may occur on the cliff, and their food preferences are unknown. Therefore, an alternative explanation may still be required. Here, we have presented evidence that the actual salt tolerance of acyanogenic cliff plants is greater than that of cyanogenic cliff plants (table 6) and therefore they may be at a selective advantage on the cliff.

The demonstration of the differential and selective grazing of acyanogenic $L$. corniculatus plants (tables 9,10 ) by $H$. itala and $C$. acuta is particularly important because these molluscs are present in large numbers in the hollow and on the mound at Porthdafarch where the frequency of cyanogenic plants is high (Ellis et al., 1977c). This coincidence of distribution is good circumstantial evidence for the defensive function of cyanogenesis in a natural population of $L$. corniculatus (Ellis et al., 1977a).

Under conditions of no grazing the glucosidic plants $(++$ and +- ) have a clear advantage with respect to pod production (table 11). Uniform grazing, on the other hand, differentially reduces the performance of all four phenotypes so that there is, essentially, little difference between them (table 11). Glearly therefore, any grazing will be deleterious to the plants, but under the conditions of selective grazing the cyanogenic plants will have a marked advantage, an advantage which may affect both vegetative and sexual reproduction. The effect on vegetative reproduction can only be assessed if pod production is correlated with the number of axillary buds and, contrary to Greub and Wedin (1971), there is no evidence from our results that moderate clipping enhances growth. Clipping at 4-weekly intervals may be too frequent and there is evidence that clipping during June does reduce seed set (Seaney and Henson, 1970).

Similarly, the effect of trampling was to reduce pod production on plants of both phenotypes of $L$. corniculatus (table 12). In ecological studies on the effect of trampling in particular habitats, Burden and Randerson (1972) found that $L$. corniculatus survives best at medium levels of trampling. This result agrees well with similar work by Liddle and Greig-Smith $(1975 b)$, in which species were given occurrence indices as convenient indications of their tolerance to trampling. L. corniculatus, with an index of 0.5 , was found to be an indicator of dry paths. In both studies it was 
considered that $L$. corniculatus may be shaded out by taller grasses in areas of no, or low, trampling, but it is sensitive to the greater pressures found on heavily trampled paths. The effect of trampling may differentiate directly between the cyanogenic and acyanogenic phenotypes by causing the release of hydrogen cyanide in ++ plants as a result of physical damage to the leaves. It could also act indirectly. by affecting the soil water availability,
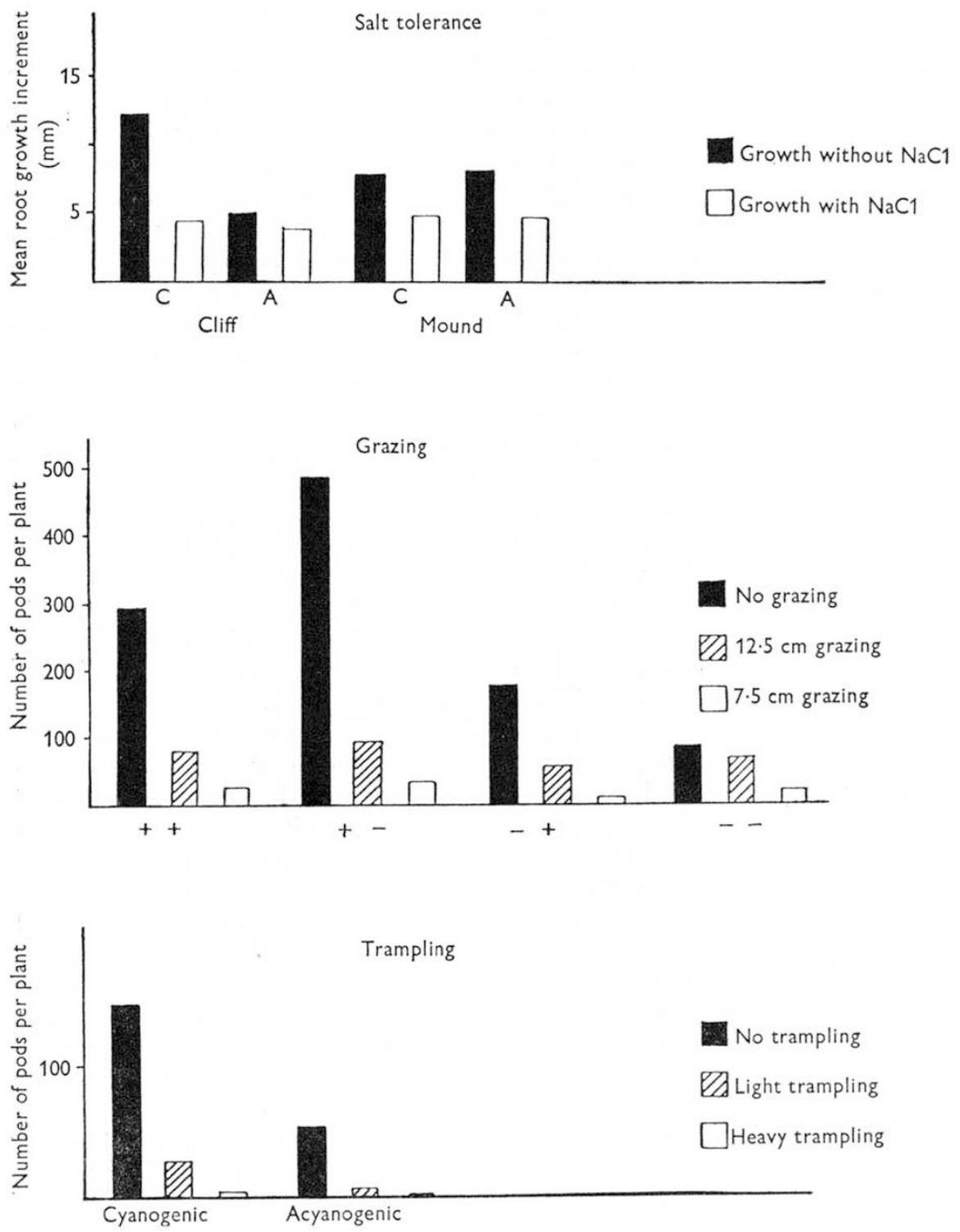

Fig. 1.-Summary of the effects of $\mathrm{NaCl}$, non-selective grazing and of trampling on $L$. corniculatus plants from Porthdafarch, Anglesey. Cloned plants were subjected to four concentrations of $\mathrm{NaCl}$ and the mean performance under these stress conditions has been used to prepare the figure. The experimental details are in the text. C, cyanogenic; A, acyanogenic. 
which may be a selective agent acting on the polymorphism (Foulds and Grime, 1972; Abbott, 1977). Our evidence is insufficient to determine differential effects, but it is clear that trampling is a significant factor in the Porthdafarch environment.

In the salt tolerance experiments, as well as in the grazing and trampling experiments, we began with the null hypothesis that the growth, reproduction and survival of the different phentoypes would be equal, if no selective stress were operating. That is, under conditions of no stress all phenotypes would grow equally well, and yet when the appropriate stress was applied they would grow differentially less well. This clearly is not so (fig. 1). In all the experiments, the cyanogenic phenotype grew better than the acyanogenic phenotype under conditions of no stress. In other words, the cyanogenic phenotype had, overall, a greater potential for growth and reproduction. The results of applying uniform selective stresses show that it is the loss of potential that differentiates between the phenotypes. Perhaps our null hypothesis should have assumed the effect of past natural selection on the plants we collected from Porthdafarch, i.e. that the growth, reproduction and survival of the different phenotypes would be equal, under selective stress. Only those plants with equal performance under stress could survive in competition in those environments. Therefore, the differences in lost potential between phenotypes, that is the potential performance minus the stress performance, is the appropriate estimate of the differential fitnesses of the phenotypes in the coastal and inland environments at Porthdafarch.

Acknowledgements.-We are most grateful to the Natural Environment Research Council and the Sir Philip Reckitt Educational Trust (research studentship, R. J. K.) and to the Science Research Council (B/RG/33539, W. M. E.) for the financial support of this work. We especially thank Miss A. K. Braithwaite and Mr V. Swetez, for their care of the glasshouse plants and reliable trampling, and Professor D. A. Jones, for his encouragement and critical reading of the manuscript.

\section{RefERENGES}

Аввотт, R. J. 1977. A quantitative association between soil moisture content and the frequency of the cyanogenic form of Lotus corniculatus L. at Birsay, Orkney. Heredity, $38,397-400$.

ARNON, D. 1., AND HOAGLAND, D. R. 1940. Crop production in artificial culture solutions and in soils with special reference to factors influencing yields and absorption of inorganic nutrients. Soil Sci., 50, 463-483.

Ayers, A. D. 1948. Salt tolerance of birdsfoot trefoil. 7. Am. Soc. Agron., 40, 331-334.

BURDEN, R., AND RANDERSON, P., 1972. Quantitative studies of the effect of human trampling on vegetation and as an aid to the management of semi natural areas. J. Appl. Ecol., 9, 439-457.

CRAWFORD-SIDEBOTHAM, т. J. 1972. The role of slugs and snails in the maintenance of the cyanogenesis polymorphism of Lotus corniculatus and Trifolium repens. Heredity, 28, 405-411.

ELLIS, W. M., KEYMER, R. J., AND JONES, D. A. $1977 a$. The defensive function of cyanogenesis in natural populations. Experientia, 23, 309-311.

ELlis, w. M., KEYMER, R. J., AND JONES, D. A. 1977b. The effect of temperature on the polymorphism of cyanogenesis in Lotus corniculatus L. Heredity, 38, 339-347.

ELLIS, W. M., KEYMER, R. J., AND JONES, D. A. 1977c. On the polymorphism of cyanogenesis in Lotus corniculatus L. VIII. Ecological studies in Anglesey. Heredity, 39, 45-65.

Foulds, W., AND GRIME, J. P. 1972. The influence of soil moisture on the frequency of cyanogenic plants in populations of Trifolium repens and Lotus corniculatus. Heredity, 28, 143-146. 
GREUB, L. J., AND WEDIN, w. F. 1971. Leaf area, dry matter production and carbohydrate reserve levels of birdsfoot trefoil as influenced by cutting height. Crop Science, 11, 734-738. HANNON, N., AND BRADSHAW, A. D. 1968. Evolution of salt tolerance in two coexisting species of grass. Nature, 220, 1342-1343.

Jameson, D. A. 1963. Responses of individual plants to harvesting. Bot. Rev. 29, 532-549. JoNEs, D. A. 1962. Selective eating of the acyanogenic form of the plant Lotus corniculatus $\mathbf{L}$. by various animals. Nature, 193, 1109-1110.

JONES, D. A. 1966. On the polymorphism of cyanogenesis in Lotus corniculatus L. I. Selection by animals. Can. 7. Genet. Cytol. 8, 556-567.

JoNEs, D. A. 1977. On the polymorphism of cyanogenesis in Lotus corniculatus L. VII. The distribution of the cyanogenic form in Western Europe. Heredity, 39, 27-44.

KEYMER, R. J. 1978. Genecological studies of cyanogenesis in Lotus corniculatus L. Ph.D. thesis, University of Hull.

LIDDLE, M. J., AND GREIG-SMITH, P. 1975a. A survey of tracks and paths in a sand dune ecosystem. I. Soils. 7. Appl. Ecol., 12, 893-908.

LIDDLE, M. J., AND GREIG-SMITH, P. 1975b. A survey of tracks and paths in a sand dune ecosystem. II. Vegetation. 7. Appl. Ecol., 12, 909-930.

malan, M. A. 1973. Preliminary studies of the ecology of the heath snail Helicella itala (L.). M.Sc. thesis, University College of North Wales, Bangor.

mCmillan, c. 1959. Salt tolerance within a Typha population. Amer. J. Bot., 46, 521-526.

mudie, P. J. 1974. The potential economic use of halophytes. In Ecology of Halophytes eds. R. J. Reynold and W. H. Queen, pp. 565-597. Academic Press Inc., New York and London.

DE NETtancourt, D., AND GRANT, W. F. 1963. The cytogenetics of Lotus (Leguminosae). II. A diploid interspecific hybrid between $L$. tenuis and L. filicaulis. Can. F. Genet. Cytol., 5, 338-347.

REPP, G., MCALLISTER, D. T., AND WIEBE, N. H. 1959. Salt resistance of protoplasm as a test for the salt tolerance of agricultural plants. Agron. 7., 51, 311-314.

seaney, R. R., AND henson, P. R. 1970. Birdsfoot trefoil. Adv. in Agron., 22, 120-157.

TIKU, B. L., AND sNAYDon, R. W. 1971. Salinity tolerance within the grass species Agrostis stolonifera L. Plant and Soil, 35, 421-431.

WAISEL, Y. 1959. Ecotypic variation in Nigella arvensis L. Evolution, 13, 469-475.

WAIsEL, Y. 1972. Biology of Halophytes. Academic Press, New York and London.

wilkiNs, D. A. 1957. A technique for the measurement of lead tolerance in plants. Nature, 180, 37-38.

WILkINS, D. A. 1960 . The measurement and genetical analysis of lead tolerance in Festuca ovina. Scottish Plant Breeding Station Report, 1960, 85-98. 